\title{
Significant Study on Artistic Characteristics of Clothing Design in Pastoral Style
}

\author{
Li Wan \\ Huanghe Science and Technology College \\ Zhengzhou, Henan, China, 450000
}

\begin{abstract}
In recent years, with the improvement of people's material and spiritual life, our previous dressing ideas are now in the melting-pot. More and more people are eager to show their self-consciousness and spiritual pursuit to the surrounding environment through their own fashion image. Therefore, it makes clothing matching art increasingly important in today's society to establish fashion image. Since the 21 st century, the pastoral style has become very popular in the international fashion circle. More and more fashion designers attach great importance to design and the matching of fashion styles. The author is aimed to find the research significance of fashion style theory by studying artistic characteristics of clothing matching in pastoral style in depth.
\end{abstract}

Keywords-pastoral style; clothing matchin; artistic characteristics; significance

\section{INTRODUCTION}

Clothing is one of material conditions created by human beings for survival, and a significant spiritual element that human beings depend on in social production activities. With highly-developed information technologies, nowadays we have a great improvement in cultural level and material life, and an obvious change in ideologies. Many people are no longer content with the physiological function clothing provides to us in pursuit of fashion, but more strongly pursue the era beauty (fashionable beauty) and the wisdom beauty (matching beauty) in clothing, and the spiritual outlook that the clothing gives to the wearer. Therefore, under the influence of this mentality, clothing style has become an important expression form of clothing matching. "The socalled fashion style refers to the unified and glamorous appearance effect formed by all the elements of fashion image with a distinct tendency". The personalized dress prevails in nowadays, so more and more distinctive clothing appears in endlessly; for example, well-known neutral style, vintage style, Lolita, OL, hip-hop style, punk style and etc. shine with their distinct charm through the carrier of clothing matching and show a strong postmodern fashion. However, the clothing in pastoral style is distinctive. With its unique, fresh design and a natural taste, the pastoral style has become the favorite of urban dwellers and the source of inspiration of world well-know fashion designers. The pastoral style is a highly artistic dressing style in clothing matching. Why this style is one very important expression in the fashion cycle? The author thinks only by studying the significance of artistic characteristics of clothing in pastoral style in depth, can we find a good theoretical basis for the popular style.

\section{HELPING AUdIENCES UNDERSTAND THE SiLHOUETTE AND Detail Design OF THE Clothing IN PAStORAL STYLE FROM THE PERSPECTIVE OF ART THEORY}

\section{A. Understanding the Silhouette of Clothing from the Perspective of Art Theory}

Clothing silhouette refers to the silhouette of external styling which is one main characteristic to determine the overall styling of clothing. We can simply classify clothing silhouette into the linear pattern and the curved pattern, but the insiders generally classify it by clothing shape which was summarized by Dior in the 1950s. Dior has used Latin alphabets to sort, such as H-shaped, A-shaped, X-shaped, Oshaped, T-shaped and so on. H-shaped clothing is characterized by no significant difference in the waist, shoulder and hip, and simple lines, which has been seen as a symbol of new women in the history of Western fashion. Ashaped clothing was first created by Mr. Dior in 1955, with its design of the A-shaped skirt for typical. A-shaped skirt is still popular with a lot of women of all ages. X-shaped clothing is characterized by broad shoulder, wasp waist and enlarging lower hem, which is a styling most conform to body form. With natural lines, the notable feminine garment is the main styling of today's modern women dress. Oshaped clothing is characterized by exaggerating waist, bending of shoulder and closing up of lower hem, which gives the outer contour of the torso with arc of different curvature and makes the clothing full and ease, and also can cover body defect of obese people with round waist. Tshaped clothing is characterized by styling of shoulder; generally its crotch and lower hem are tightening; the contour seems solemn, graceful and easy.

\section{B. Understanding the Detail Design of the Clothing in Pastoral Style from the Perspective of Art Theory}

The detail design of clothing in pastoral style refers to the basic composition parts of tops and bottoms, which help audiences understand the relationship between clothes and human body better. The relationship is mainly showed in the design of clothing parts. The basic components of tops are collar, sleeves, pocket, button and other accessories. The clothing in pastoral style generally is designed with neckline 
or lapel. The clothing with neckline seems simple and graceful, conducive to show neck line and beauty. For example, boat neckline, square neckline, V-shaped neckline and etc. are often used in the design of clothing in pastoral style. In addition, many pastoral style shirts are designed with lapel which is an outward-turning collar. The pastoral style lapel skirt with painted design could give us a sense of nature. The detail design of sleeve is also a key point to size up the pastoral style, especially for spring and summer clothing. For example, the pastoral style clothing with no sleeve, three quarter sleeves, puff sleeves, and other styling are very common in our daily life. These sleeve designs are concise, fluent and cater to the ease and graceful requirement for the pastoral style clothing. The bottoms pants are composed of pant legs and pant waist and pockets, which may derive different styles with different length of legs, waist and different size of leg opening. For example, we often see turnip pants, loose pants, and other bottoms in typical pastoral style. These design details can be clearly reflected whether it is a garment in pastoral style or not.

\section{Helping Audiences Improve the AESTHETIC TASTE IN DRESSING}

On one hand, aesthetics plays a very important role in the artistic creation and art appreciation. Most of clothing in pastoral style are bright-colored and with distinctive styles. It may make audiences think why this art form has these characteristics by studying artistic characteristics of fashion design in this style, and help audiences understand the nature content of this art form by means of fashion design. In the thinking process about various design forms and elements, we certainly will appreciate, study and research these elements, composition and contents. In other words, we will analyze this art form detailedly. In this process, people constantly understand, evaluate, feel, appreciate and enjoy the beauty of design, which helps people improve and sublimate self aesthetic consciousness.

On the other hand, the clothing in pastoral style are becoming more and more popular, because this unique design brings people back to vital nature and gives people a fresh feeling. This kind of temperament and the free, comfortable artistic conception attract urban dwellers under great pressure to choose it. Therefore, most clothing in pastoral style are casual, comfortable and elegant, with simple, quiet and beautiful temperament. People loving this clothing style may expect to express their desire to get rid of the noisy city and return back to nature by wearing clothing in pastoral style. It is undeniable that clothing in pastoral style has a very important influence on people's psychological demands, so that it attracts and leads people's the clothing aesthetic orientation to a great extent. We can understand it like this: the style, color, shape and other elements of clothing in pastoral style can cause association to ideal life and emotional resonance with aid of sensory functions of human beings, thus resulting in a series of psychological activities. This aesthetic phenomenon refers to the "empathy" in aesthetics.

\section{HELPING AUdiEnCES Understand THE PROFESSIONAL DRESSING CRITERION}

Sociologist Erving $\cdot$ Goffman had proposed: dressing is part of our effort to put ourselves in a social system. Entering in twenty-first century, the association between society, life, environment and people is becoming closer, and closer, and people must involve in every part of the society, which determines that the clothing beauty is mobile, social, and influenced by social environmental factors. Fashion design should adapt to environment so as to produce aesthetic perception. If beautiful fabrics, style and styling do not match with environment, it cannot cause aesthetic effect. Here, we have to mention the "T.P.O principle".

\section{A. Clothing Matching and Time}

The time, said here, includes change of seasons and day alternate, so that we should select clothing type and style according to the season and the difference of day and night. For example, in cold winter, we should wear warm clothes and down clothes to fight against cold; in hot summer, we should wear ventilating, sweat-absorbing and cool summer clothes, such as skirt, dress and etc.; by day, we should wear neat, elegant and decent clothes in order to go out for study or work; at night, we should be particular about clothes if we go to party; we can wear formal wear or beautiful party dresses; if it is unnecessary, we can select loose, casual and comfortable nightgown or leisure clothes at home.

\section{B. Clothing Matching and Place}

The place refers to the position where people participate in social activities. In different places, indoor or outdoor, in city or in country, in company or at home, we should change our dress style along with the change of place. It is not wise to appear in various places with same dress. For example, we cannot wear pajamas or home wear to go to work, nor wear swimsuit to go downtown. Some countries have very strict requirements on dressing. For example, in North Korea, women can't wear pants; in Arabia countries, women wearing mini-skirt or backless dress will be regarded as not respecting their ethnic customs.

\section{Clothing Matching and Occasion}

Purposiveness is a very important content in dress etiquette. Modern people are very concerned about their dressing expression to others in social contact. Therefore, they often express their willingness by adjusting their clothes to achieve the desire. For example, it is a kind of respect to other by wearing formal clothes in business occasion; it is presumptuous to wear outlandish costume in formal occasion. Applicants can show respect to interviewers by wearing Western dress and leather shoes in the interview. If someone wears T-shirt and shorts to participate in the interview, he/she will be regarded to be decadent. All of these mean people can express themselves by clothing style in various social occasions. Therefore, it is very important to wear right clothes and match clothes properly in different occasions. 


\section{PROVIDING ABUndant DESIGN ElEMENTS to DESIGNERS}

The artistic characteristic of fashion design is the external expression of the design nature. It helps fashion designers understand the nature of fashion design in depth by researching artistic characteristics of fashion design. Only by knowing all elements of fashion design very well, can they use them flexibly in design. It also can help them get a lot of design inspiration and abundant design elements.

\section{A. Inspiration from Nature}

In general, the clothing works in pastoral style have three characteristics. "The first is the natural decoration. The designer's inspiration often comes from the natural scenery, trees, flowers, rocks, sand, blue sky, the sea, the sun, the moon, and stars... Like an old saying, "the natural and beautiful lotus comes from clear water with no showy decoration'. It pursues the simple and natural effect. The second is that it conforms to human body. The works in this style mostly are going along with human body to show natural beauty and life charm of main image. It fights against shaping human body and stresses comfort, relax and elegance, so it is easy to human activities. Casual and leisure wear are relaxed and give a tranquil sense, easier to be designed in pastoral style. In recent years, it appear a trend that people like wear leisure clothing to participate in official and corporate business activities. The third is the natural fabric which is the material base of clothing in pastoral style. The direct effect of natural pursuit is the beauty and comfort sensation, which perfectly integrates the psychological factor and physiological factor."

\section{B. Inspiration from the Environmental Protection}

In the twenty-first century, people pay more attention to environmental protection. Since the industrial revolution in Britain in eighteenth century, along with the continuous improvement of the social productive forces, the machine production has replaced manual labor, and brought the rapid development of urbanization and industrialization, and dramatic changes to our daily life and ideas. At same time, there appear a lot of new social problems, such as population expansion, crowded housing, traffic jams, environment pollution, climate deterioration and etc. The destruction of modern industrial pollution to the natural environment, manmade disasters, high-tempo nervous life and so on, has brought us all sorts of mental pressure. Science and technology hurt the nature in helping us understand nature, but nowadays people prefer green, natural, authentic and pure science and technology. The environmental protection, low carbon and other various good concepts are becoming more and more fashionable and popular. These concepts are also the source of inspiration in designing pastoral style clothing. It has become the common theme of pastoral style designers to select natural and environmental-protection fabrics to produce clothing in pastoral style and adhere to the principle of simple, comfortable and resource-saving concept. Modern people become more and more tired of city life, so they prefer fresh and natural clothing in pastoral style. In addition, the fresh and natural pastoral style is endowed with a distinct sense of the times by adding modern design elements into it.

\section{Reflecting the NeEd OF MOdERn PEOPLE For SPIRITUAL LIFE}

People originally were derived from nature, but with the development of society, man is alienated from the inner self. The brilliant metropolitan life makes people become bored and feel abandoned by nature. We are far away from plenty of sunshine, fresh air, quiet forests and clear streams. It has become a very extravagant idea to get close to nature. However, the clothing in pastoral style and its design style are in line with the ideas of urban dwellers to return back to nature after the busy work, which reveals human's yearning for the beauty of soul and nature. Therefore, we can find people's spiritual demand. Whether for pastoral style clothing designer or for people who love this clothing style, they have a spiritual need and a yearning for nature in their heart and yearn for the life standing aloof from worldly success.

The clothing in pastoral style brings people the simple and elegant sensual pleasure with its unique visual effect and style. It pursues the comfortable, soft and pendent effect, and stresses environmental protection and other fashionable concepts, so as to adapt to the modern aesthetic and consumption values. It also caters to the modern people's continuous exploration and pursuit for "the true, the good and the beauty". "It is the best times, and it also is the worst times" noted by Mr. Nan Huaijin ten years ago, "nowadays due to the contribution of western culture, our material civilization is very developed. For example, we have convenient transportation, luxury building and ease life. It seems that it is the happiest time in the history. However, people survive and compete busily. People are frightened and restless because of wars, and troubled with their worldly desires. From the spiritual view, it is the most painful era in the history. Under the sharp contrast of developed material civilization and spiritual poverty, man is now facing a new crisis". Perhaps Mr. Nan's words explain the unique spiritual connotation of clothing in pastoral style.

\section{REFERENCES}

[1] Wang Yuan. Clothing Matching Art. Beijing: China Textile Press, 2009.

[2] Liu Lei \& Hou Jiahua. Costume Aesthetics. Beijing: Chemical Industry Press, 2009.

[3] Zhu Guangqian. Western Aesthetic History. Beijing: China Chang'an Publishing House, 2007.

[4] Wang Hongjian. Introduction to Art. Beijing: Culture and Art Publishing House, 2000.

[5] Zhang Xing. Clothing Fashion. Beijing: China Textile Press, 2006.

[6] Plekhanov. Letter with No Address. Beijing: People's Literature Press, 1962.

[7] Rodin. Rodin Art Theories. Beijing: People's Fine Arts Publishing House, 1978

[8] Wang Hongjian. Introduction to Arts. Beijing: Culture and Arts Publishing House, 2001. 
[9] Li Yingqun \& Fan Tieming. Analysis on Modern People's Need for Spiritual Life by Clothing in Pastoral Style. Journal of Popular Literature and Art, Jun. 2010.

[10] Xu Pingshan. Analysis on Clothing Art Style. Journal of Movie Review, Oct. 2009. 